\begin{tabular}{lc|c|c|}
\hline Bentham open & The Open Rheumatology Journal & $\begin{array}{l}\text { The Open } \\
\text { Rheuratology } \\
\text { lournal }\end{array}$ \\
\hline CrossMark & Content list available at: www.benthamopen.com/TORJ/ & DOI: $10.2174 / 1874312901610010081$ \\
\hline
\end{tabular}

RESEARCH ARTICLE

\title{
Arthritis of the Knee Joint in Rheumatoid Arthritis - Evaluation of Treatment Response by Ultrasound in Daily Clinical Practice
}

\author{
VS Schäfer ${ }^{*}, 1$, WA Schmidt ${ }^{1}$, M Backhaus ${ }^{2}$ and W Hartung ${ }^{3}$ \\ ${ }^{1}$ Immanuel Krankenhaus Berlin, Medical Centre for Rheumatology and Clinical Immunology Berlin-Buch, \\ Lindenberger Weg 19, 13125 Berlin, Germany \\ ${ }^{2}$ Department of Internal Medicine, Park-Klinik Weißensee, Rheumatology and Clinical Immunology, Schönstraße 80, \\ 13086 Berlin, Germany \\ ${ }^{3}$ Department of Rheumatology and Clinical Immunology, Asklepios Clinic, Kaiser-Karl-V.-Allee 3, Bad Abbach, \\ Germany
}

Received: June 21, 2016

Revised: October 19, 2016

Accepted: October 19, 2016

\section{Abstract: \\ Background:}

Rheumatoid arthritis (RA) commonly involves the knee joint in up to $30 \%$ of patients. Musculoskeletal ultrasound enables the skilled clinician to easily assess disease activity.

\section{Objective:}

To evaluate the sensitivity to change of the sonography score of large joints in Rheumatology (SOLAR) for different treatments of knee arthritis in RA.

Method:

Joints were assessed by ultrasound at 4 visits. Laboratory, immunological and clinical parameters were recorded.

Results:

225 RA patients were analyzed. The DAS 28 in the subgroup receiving systemic steroids was significantly higher $(\mathrm{p}<0.001)$ than in patients treated with intraarticular glucocorticosteroids (GCs) at T0, comparing the values from T0 to T3 the same appeared $(\mathrm{p}=0.003$ ). Concerning the acute GC treatment regimens, the gray scale ultrasound (GSUS) sum score was found to be significantly higher in patients receiving intraarticular GCs versus no GCs $(\mathrm{p}=0,035)$, as well as in patients receiving systemic versus intraarticular GCs $(p=0.001)$. Regarding the differences from T0 and T3, similar to the baseline analysis, a high GSUS sum score was significantly associated with intraarticular GCs, a low to no GC administration ( $\mathrm{p}=0.035)$, while a high GSUS sum score was significantly linked to intraarticular GCs, rather than systemic GCs $(\mathrm{p}=0.008)$.

\section{Conclusion:}

SOLAR score is sensitive to change in knee arthritis. Intraarticular GC administration is performed in patients with high GSUS scores. Systemic administration of GC is linked to high disease activity (DAS28) rather than GSUS or power Doppler ultrasound (PDUS) results.

Keywords: Glucocorticosteroids, Knee joint, Musculoskeletal ultrasound, Nonsteroidal anti-inflammatory drugs, Rheumatoid arthritis, Therapy, Ultrasound.

\footnotetext{
* Address correspondence to this author at the Immanuel Krankenhaus Berlin, Medical Centre for Rheumatology and Clinical Immunology BerlinBuch, Lindenberger Weg 19, 13125 Berlin, Germany; Tel: +49 3094792 306; Fax: ++49 3094792 550; E-mail: valentin.s.schaefer@hotmail.de
} 


\section{INTRODUCTION}

Musculoskeletal ultrasound (MSUS) is nowadays commonly used as an imaging tool in the evaluation of rheumatoid arthritis (RA). Research in the last decade has focused mainly on the assessment of disease activity in small joints in RA using MSUS [1 - 3], while large joints have not been extensively studied so far. Knee joint involvement has not been mentioned by most recent ultrasound scores, it is only included in few ultrasound scores like the 12 joint MSUS score by Naredo et al. [2] and in a lately published SOLAR score [4, 5], which is focused on large joints in RA, psoriatic arthritis and ankylosing spondylitis.

MSUS enables the skilled examiner to visualize early soft tissue changes and bony erosions, which was already shown and was proven to be superior to conventional x-ray examinations almost 14 years ago by Wakefield et al. [3]. MSUS exhibits no patient comorbidity related limiting factors, like there are for MRI examinations and allows a dynamic examination of inflamed joints by gray scale ultrasound (GSUS) and power Doppler ultrasound (PDUS). MSUS proved to be superior to clinical examination and conventional x-ray examination and showed a good correlation to MRI in RA [6]. Large joints are often involved in RA. The knee in particular is affected in about 30\% of RA patients and significantly more often bilateral than unilateral [7]. Amor et al. [8] published that large joint involvement represents an important prognostic factor associated with radiographic progression. Furthermore knee joint arthritis is a major factor leading towards functional impairment and disability in RA patients [9]. In this study we analyzed RA patients with knee arthritis, its MSUS results in the different patient treatment cohorts (nonsteroidal anti-inflammatory drugs (NSAIDs), conventional synthetic disease modifying antirheumatic drugs (csDMARDs), biological original disease modifying antirheumatic drugs (boDMARD) or a combination) and the different GSUS and PDUS results with the applied acute glucocorticoid (GC) treatment regimens. Our objective was to evaluate the sensitivity to change of the SOLAR ultrasound score [4] for different treatment regimens of knee arthritis in patients with rheumatoid arthritis.

\section{MATERIAL AND METHODS}

We used a semiquantitative scoring system, which was recently published [4]. A cohort of 225 RA patients with knee joint arthritis was examined at 4 visits [baseline (T0), 3 months (T1), 6 months (T2) and 12 months (T3)]. The affected knee joint in each individual patient was sonographically evaluated with GSUS and PDUS in the different treatment cohorts (NSAIDs, csDMARDs, boDMARDs or a combination) after the initiation of therapy, or change of the established treatment. In this multicenter study, each patient was assessed by the same sonographer, using the same ultrasound machine in the follow up examinations.

Furthermore we documented and considered additional acute treatment therapies, such as intraarticular GCs, systemic GCs, intraarticular and systemic GCs and no GCs. In addition, laboratory and clinical parameters were determined.

\section{Clinical Assessment}

At baseline and after 3, 6 and 12 months, knees of 225 RA patients were clinically assessed for swelling and tenderness. The patient rated visual analog scale for disease activity (range 0-100) was also reported at each patient's visit. In addition, the following data were documented on report sheets: year of birth, sex, height, weight, onset of typical symptoms, current rheumatologic therapy including NSAIDs, csDMARDs, boDMARDs, as well as the acute therapy with systemic, intraarticular or no GC treatment at each visit.

\section{Disease Activity Assessment}

The Disease Activity Score in 28 joints (DAS28) was used to assess disease activity at each visit.

\section{Laboratory Evaluation}

Erythrocyte sedimentation rate (ESR, normal levels $<20 \mathrm{~mm} /$ hour) was obtained at each visit. IgM rheumatoid factor (RF; normal levels $<24 \mathrm{IU} / \mathrm{ml}$ ) and anti-cyclic citrullinated peptide (anti-CCP) antibodies (normal levels $<20$ units/ml) were determined at baseline.

\section{US Examination}

The knee was sonographically examined by GSUS and PDUS in a standardized modified manner according to the German [10] and European League against Rheumatism (EULAR) [11] guidelines at baseline and the follow up visits 
(3,6 and 12 months).

\section{GSUS}

Synovitis by GSUS was analyzed semiquantitatively from 0 to $3(0=$ absence, $1=$ mild, $2=$ moderate, $3=$ severe, (Table 1)) as described recently [4]. The knee joint was divided into four planes to score for synovitis: the suprapatellar longitudinal scan, the medial longitudinal scan, the lateral longitudinal scan, and the posterior longitudinal scan (Table 1).

Table 1. GSUS Scanning planes for the knee (maximal score 12).

\begin{tabular}{|c|c|c|c|c|c|}
\hline Nr. & Plane & Grade 0 & Grade 1 & Grade 2 \\
\hline 1. & Suprapatellar longitudinal & normal & JCD parallel to the femur bone & JCD straight \\
\hline 2. & $\begin{array}{c}\text { Medial longitudinal of femuro- } \\
\text { tibial joint }\end{array}$ & normal & $\begin{array}{c}\text { JCD parallel to bone no distension } \\
\text { over the joint space }\end{array}$ & $\begin{array}{c}\text { JCD parallel to bone distension } \\
\text { above the joint space }\end{array}$ & $\begin{array}{c}\text { JCD convex above the } \\
\text { joint space }\end{array}$ \\
\hline 3. & $\begin{array}{c}\text { Lateral longitudinal of femuro- } \\
\text { tibial joint }\end{array}$ & normal & $\begin{array}{c}\text { JCD parallel to bone no distension } \\
\text { over the joint space }\end{array}$ & $\begin{array}{c}\text { JCD parallel to bone distension } \\
\text { above the joint space }\end{array}$ & $\begin{array}{c}\text { JCD convex above the } \\
\text { joint space }\end{array}$ \\
\hline 4. & Posterior longitudinal & normal & slight JCD over the jointspace & $\begin{array}{c}\text { JCD parallel to bone, distension } \\
\text { over the joint space }\end{array}$ & $\begin{array}{c}\text { JCD convex above the } \\
\text { joint space }\end{array}$ \\
\hline
\end{tabular}

JCD: joint capsule distension

\section{PDUS: Synovitis by PDUS}

was performed in each scanning plane as described above. In addition the infrapatellar longitudinal scan was scored for hypervascularisation. The semiquantitative findings of PDUS activity for synovitis were scored as follows: Grade 0 $=$ no intraarticular colour signal, grade $1=$ up to 3 single colour signals or 2 single colour signals and 1 confluent colour signal representing only low flow, grade $2=$ greater than grade 1 to $<50 \%$ of the intraarticular area filled with colour signals representing clear flow, grade $3=>50 \%$ of the intraarticular area filled with colour signals [12].

A sum score (Table 1) for the knee was applied according to a recently published scoring system for large joints [4], including the sum of the synovitis scores in the GSUS and the PDUS modes. The range for the sum score for the knee was $0-12$ in GSUS and 0-15 in PDUS.

\section{Statistical Analysis}

Statistical analysis was performed with SPSS statistical software, version 17.02 (SPSS, Chicago, IL). For quantitative parameters (e.g., number of patients, age of examined patients, and their disease activity), the mean and +/$\mathrm{SD}$ and range were determined. Significant changes were calculated by the Kruskal-Wallis-Test. P - values less than 0.05 were considered statistically significant. The difference between two groups was calculated using the MannWhitney-U Test, values less than 0.05 were considered statistically significant.

\section{RESULTS}

\section{Patient Characteristics}

A cohort of 225 RA patients with knee arthritis (68\% women) with a mean age of $54.9 \pm 13.1$ years was examined. All patients had RA according to the ACR Criteria of 2010 [13]. At inclusion, 56\% of patients ( $\mathrm{n}=125)$ were RF positive and $44 \%$ of patients $(n=100)$ were tested positive for anti-CCP antibodies. The mean duration of symptoms was 87.9 months \pm 93.2 .

\section{Medication}

At baseline 80 patients were treated with NSAIDS, most commonly used were, diclofenac $(n=24)$, ibuprofen ( $n=$ 18), etoricoxibe $(n=18)$ and celecoxibe $(n=9) .199$ patients received a csDMARD alone or in combination with another csDMARD, as well as a combination of csDMARD and boDMARD. The most commonly used csDMARDs were methotrexate $(n=139)$, leflunomide $(n=34)$ and sulfasalazine $(n=14)$. Altogether 71 patients received a boDMARD therapy with adalimumab $(n=47)$, etanercept $(n=14)$, golimumab $(n=6)$, infliximab $(n=3)$ or tocilizumab $(n=1)$ respectively.

A total of $88.4 \%$ (199) of the patients received GCs $(57.8 \%$ (130) systemic administration, $20 \%$ (45) systemic and intraarticular administration and 10.7\% (24) only intraarticular injections). 11. 6\% (26) never received GCs. 
During the 12 months observation period, the immunosuppressive treatment has been adjusted for each RA patient individually based on the clinical findings and experience by the treating rheumatologist.

\section{Laboratory and Clinical Parameters}

The mean ESR was $34.9 \mathrm{~mm} / \mathrm{h} \pm 25.1$ while the median DAS 28 was $4.60(3.60-5.70)$. The DAS28 revealed a significant higher disease activity $(\mathrm{p}=0,001)$ in the group which received systemic GCs than in the group receiving only intraarticular GCs at baseline (T0), while significant values $(p=0,003)$ were reached between these groups comparing T3 to T0. The exact values for each group are listed in (Table 2).

Table 2. Laboratory and ultrasound parameter.

\begin{tabular}{|c|c|c|c|c|c|c|}
\hline Parameter & & $\begin{array}{c}\text { Total } \\
(n=225)\end{array}$ & $\begin{array}{c}\text { Group 1 } \\
(\mathrm{n}=\mathbf{2 6})\end{array}$ & $\begin{array}{l}\text { Group 2 } \\
(n=130)\end{array}$ & $\begin{array}{c}\text { Group } 3 \\
(\mathrm{n}=24)\end{array}$ & $\begin{array}{c}\text { Group } 4 \\
(n=45)\end{array}$ \\
\hline ESR & & $\mathrm{n}=211$ & $\mathrm{n}=24$ & $\mathrm{n}=122$ & $\mathrm{n}=22$ & $\mathrm{n}=43$ \\
\hline \multirow[t]{3}{*}{ T0 } & mean. & 34,9 & 27,5 & 37,0 & 27,3 & 37,1 \\
\hline & $\pm \mathrm{Std}$ & 25,1 & 21,8 & 25,8 & 21,4 & 26,0 \\
\hline & & $\mathrm{n}=202$ & $\mathrm{n}=22$ & $\mathrm{n}=121$ & $\mathrm{n}=21$ & $\mathrm{n}=38$ \\
\hline \multirow[t]{3}{*}{$\mathrm{T} 1$} & mean. & 24,1 & 25,9 & 25,0 & 23,5 & 20,7 \\
\hline & $\pm \mathrm{Std}$ & 19,1 & 17,0 & 20,2 & 18,8 & 15,2 \\
\hline & & $\mathrm{n}=202$ & $\mathrm{n}=23$ & $\mathrm{n}=120$ & $\mathrm{n}=22$ & $\mathrm{n}=37$ \\
\hline \multirow[t]{3}{*}{$\mathrm{T} 2$} & mean. & 24,6 & 25,8 & 26,2 & 21,1 & 20,4 \\
\hline & $\pm \mathrm{Std}$ & 44,5 & 15,0 & 56,2 & 19,6 & 15,2 \\
\hline & & $\mathrm{n}=213$ & $\mathrm{n}=25$ & $\mathrm{n}=125$ & $\mathrm{n}=22$ & $\mathrm{n}=41$ \\
\hline \multirow[t]{2}{*}{ T3 } & mean. & 20,0 & 21,6 & 20,0 & 18,0 & 19,9 \\
\hline & $\pm \mathrm{Std}$ & 17,0 & 11,4 & 17,9 & 14,8 & 18,6 \\
\hline DAS28 & & $\mathrm{n}=216$ & $\mathrm{n}=24$ & $\mathrm{n}=125$ & $\mathrm{n}=23$ & $\mathrm{n}=44$ \\
\hline \multirow[t]{3}{*}{ T0 } & mean. & 4,69 & 4,03 & 5,05 & 3,76 & 4,56 \\
\hline & $\pm \mathrm{Std}$ & 1,41 & 0,945 & 1,48 & 1,08 & 1,19 \\
\hline & & $\mathrm{n}=210$ & $\mathrm{n}=26$ & $\mathrm{n}=120$ & $\mathrm{n}=23$ & $\mathrm{n}=41$ \\
\hline \multirow[t]{3}{*}{$\mathrm{T} 1$} & mean. & 3,52 & 2,89 & 3,63 & 3,76 & 3,62 \\
\hline & $\pm \mathrm{Std}$ & 1,32 & 0,994 & 1,36 & 1,08 & 1,28 \\
\hline & & $\mathrm{n}=218$ & $\mathrm{n}=26$ & $\mathrm{n}=125$ & $\mathrm{n}=24$ & $\mathrm{n}=43$ \\
\hline \multirow[t]{3}{*}{$\mathrm{T} 2$} & mean. & 3,41 & 2,95 & 3,47 & 3,33 & 3,57 \\
\hline & $\pm \mathrm{Std}$ & 1,20 & 0,985 & 1,31 & 0,989 & 1,02 \\
\hline & & $\mathrm{n}=219$ & $\mathrm{n}=25$ & $\mathrm{n}=128$ & $\mathrm{n}=23$ & $\mathrm{n}=43$ \\
\hline \multirow[t]{2}{*}{ T3 } & mean. & 3,14 & 3,08 & 3,14 & 3,08 & 3,22 \\
\hline & $\pm \mathrm{Std}$ & 1,34 & 0,883 & 1,34 & 1,30 & 1,59 \\
\hline GSUS sum score & $\mathrm{n}=206$ & $\mathrm{n}=26$ & $\mathrm{n}=121$ & $\mathrm{n}=22$ & $\mathrm{n}=37$ & \\
\hline \multirow[t]{3}{*}{ T0 } & mean. & 5,33 & 5,27 & 4,98 & 6,23 & 6,00 \\
\hline & $\pm \mathrm{Std}$ & 2,97 & 3,03 & 2,84 & 3,18 & 3,10 \\
\hline & & $\mathrm{n}=209$ & $\mathrm{n}=25$ & $\mathrm{n}=120$ & $\mathrm{n}=23$ & $\mathrm{n}=41$ \\
\hline \multirow[t]{3}{*}{$\mathrm{T} 1$} & mean. & 3,08 & 2,72 & 3,08 & 4,04 & 2,73 \\
\hline & \pm Std & 2,74 & 2,88 & 2,76 & 2,82 & 2,51 \\
\hline & & $\mathrm{n}=209$ & $\mathrm{n}=26$ & $\mathrm{n}=120$ & $\mathrm{n}=21$ & $\mathrm{n}=42$ \\
\hline \multirow[t]{3}{*}{$\mathrm{T} 2$} & mean. & 2,45 & 2,19 & 2,46 & 2,57 & 2,52 \\
\hline & $\pm \mathrm{Std}$ & 2,48 & 3,09 & 2,40 & 2,16 & 2,53 \\
\hline & & $\mathrm{n}=220$ & $\mathrm{n}=26$ & $\mathrm{n}=126$ & $\mathrm{n}=24$ & $\mathrm{n}=44$ \\
\hline \multirow[t]{2}{*}{ T3 } & mean. & 2,09 & 2,04 & 2,06 & 2,25 & 2,11 \\
\hline & \pm Std & 2,45 & 2,82 & 2,46 & 2,33 & 2,67 \\
\hline
\end{tabular}

Group 1: no GC administration, Group 2 only systemic GC, Group 3 only intraarticular GC, Group 4 both intraarticular and systemic GC.

\section{Ultrasound Results}

The sum scores were analyzed in the four treatment groups (Table 1). There were no statistical significant differences in the four treatment groups at enrollment of the study $(p=0.137)$ concerning GSUS, while the median PDUS sum score showed to be significantly $(\mathrm{p}=0.014)$ linked to the treatment intensity group, being the highest in the boDMARD group. 
Table 3 displays the PDUS sum scores from T0 (baseline) to T3 (after 12 months) for all treatment groups. The PDUS sum score revealed a highly significant treatment response as shown in the corresponding table.

Table 3. PDUS sum scores for the knee for all treatment groups.

\begin{tabular}{|c|c|c|}
\hline T0 & $3.42 \pm 4,68$ & \multirow{2}{*}{$* 0<0.001 *$} \\
\hline T1 & $1.60 \pm 2,17$ & \\
\hline T2 & $1.12 \pm 2,07$ & \\
\hline T3 & $0.81 \pm 1,52$ & \\
\hline
\end{tabular}

$P$ value was calculated using the Kruskal-Wallis-Test, ${ }^{*} \mathrm{p}<0.01$.

For all patients we documented and analyzed the acute GC treatment regimens (systemic, intraarticular, systemic and intraarticular or none) at T0 (baseline). The results are summed up in Table 4. A highly significant difference (p $=0.008$ ) was found in the GSUS sum score between intraarticular GCs and no GCs, as well as between intraarticular and systemic GCs $(\mathrm{p}=0.001)$. The PDUS sum score between systemic and no GCs was found to be almost significant $(\mathrm{p}=0.063)$.

Table 4. Acute GC treatment regimens at baseline (T0).

\begin{tabular}{|c|c|c|c|c|}
\hline Treatment regimen & GSUS sum score & p value & PDUS sum score & p value \\
\hline Intraarticular GCs & $6.63 \pm 3.27$ & \multirow{3}{*}{$\mathrm{p}=0.008^{*}$} & $3.80 \pm 3.58$ & \multirow{3}{*}{$\mathrm{p}=0.160$} \\
\hline$v s$. & & & & \\
\hline No GCs & $4.77 \pm 3.04$ & & $2.39 \pm 2.68$ & \\
\hline Systemic GCs & $4.88 \pm 2.78$ & \multirow{3}{*}{$\mathrm{p}=0.647$} & $3.63 \pm 5.23$ & \multirow{3}{*}{$\mathrm{p}=0.063$} \\
\hline$v s$. & & & & \\
\hline No GCs & $4.77 \pm 3.04$ & & $2.39 \pm 2,68$ & \\
\hline Intraarticular GCs & $6.63 \pm 3.27$ & \multirow{3}{*}{$\mathrm{p}=0.001 *$} & $3.80 \pm 5.58$ & \multirow{3}{*}{$\mathrm{p}=0.727$} \\
\hline$v s$ & & & & \\
\hline Systemic GCs & $4.88 \pm 2.78$ & & $3.63 \pm 5.23$ & \\
\hline
\end{tabular}

Mean values \pm SD. P value was calculated using the Mann-Whitney-U-Test, ${ }^{*} \mathrm{p}<0.01$.

Furthermore we analyzed the response to the acute GC treatment therapies and the differences concerning the GSUS and PDUS sum scores between T0 and T3 (after 12months). The results are displayed in Table 5. Similar to the baseline analysis, we found a significant difference between the GSUS scores concerning intraarticular versus no GC therapy $(p=0.035)$ and a highly significant difference $(p=0.008)$ regarding intraarticular versus systemic GC therapy.

Table 5. Response to acute GC treatment therapies between T0 - T3.

\begin{tabular}{|c|c|c|c|c|}
\hline Treatment regimen & GSUS sum score & p value & PDUS sum score & p value \\
\hline Intraarticular GCs & $4.71 \pm 3.54$ & \multirow{3}{*}{$\mathrm{p}=0.035^{*}$} & $3.26 \pm 3.83$ & \multirow{3}{*}{$\mathrm{p}=0.362$} \\
\hline vs. & & & & \\
\hline No GCs & $2.88 \pm 2.80$ & & $2.10 \pm 2.38$ & \\
\hline Systemic GCs & $2.90 \pm 3.20$ & \multirow{3}{*}{$\mathrm{p}=0.993$} & $2.72 \pm 5.50$ & \multirow{3}{*}{$\mathrm{p}=0.716$} \\
\hline vs. & & & & \\
\hline No GCs & $2.88 \pm 2.80$ & & $2.10 \pm 2.38$ & \\
\hline Intraarticular GCs & $4.71 \pm 3.54$ & \multirow{3}{*}{$\mathrm{P}=0.008^{* *}$} & $3.26 \pm 3.83$ & \multirow{3}{*}{$\mathrm{p}=0.454$} \\
\hline vs. & & & & \\
\hline Systemic GCs & $2.90 \pm 3.20$ & & $2.72 \pm 5.50$ & \\
\hline
\end{tabular}

Mean values \pm SD. P value was calculated using the Mann-Whitney-U-Test, ${ }^{*} \mathrm{p}<0.05 ;{ }^{* *} \mathrm{p}<0.01$.

\section{DISCUSSION}

Concerning disease activity, the DAS28 score was found to be higher in patients receiving systemic GCs than those which had only intraarticular GCs at baseline $(\mathrm{p}=0.001)$ as well as comparing T3 to T0 ( $\mathrm{p}=0.003)$. This result may implicate that the DAS28 was used among physicians to decide whether to inject intraarticular GCs or whether to give a systemic administration of GCs, as lower disease activity may not need systemic GCs. The Danish CIMESTRA study [14] found that intraarticular GCs in small and large peripheral joints resulted in rapid, effective and long lasting reduction of inflammation. Landewé et al. [15] described that an initial 6-month cycle of intensive combination treatment that includes high-dose corticosteroids, results in sustained suppression of the rate of radiologic progression in 
RA patients, independent of subsequent antirheumatic therapy. So achieving early disease control with either intraarticular or systemic GCs is of high importance.

The PDUS score in our cohort showed to be strongly linked to the treatment intensity group, being found to be the highest in patients receiving boDMARDs, which reflect the current clinical situation as a high PDUS is associated with a high disease activity and the degree of joint destruction [16].

For all treatment groups the PDUS sum score decreased significantly $(\mathrm{p}=0.014)$ showing that physicians achieved a good control of inflammation within the 12 months of observation.

The analysis of the acute GC treatment regimens in GSUS at T0 (Table 4) revealed a significant result $(p=0.01)$ between intraarticular GCs and no GCs groups, as well as between intraarticular and systemic GCs groups ( $p=0.001$ ), while the difference of the PDUS score was found to be almost significant between groups $(p=0.063)$ at T0. Looking at the difference between T0 and T3 in GSUS (Table 4) we found the same to apply, significant results in GSUS were found comparing intraarticular to no GCs $(p=0.035)$ and between intraarticular and systemic GCs $(p=0.008)$, while the PDUS did not show to be significant. These results interestingly display, that a high GSUS score leads to the administration of intraarticular GCs while a low GSUS score to no GC administration. Further GSUS score is used among physicians to decide whether to administer systemic or intraarticular GCs. Surely not only the ultrasound results, but also the pain or joint mobility restriction could have influenced the decision of the physician to inject GCs. There is a trend $(\mathrm{p}=0.063)$ that physicians used the PDUS to decide whether to administer systemic or no GCs at T0.

One major limitation of our study is that different sonography devices and probes were used by different physicians to document the MSUS results. The numbers of patients receiving systemic and local GCs were not equal, so statistical results could have been influenced by that fact. The modification of the immunosuppressive therapy during the followup could have interfered with the analysis of the results. Furthermore patients received different additional medical therapies, according to their co morbidities, which could have influenced our results.

\section{CONCLUSION}

In conclusion, this study suggests that MSUS and especially GSUS is commonly used among rheumatologists in Germany to decide whether to administer systemic, intraarticular or no GCs, while the PDUS did not show to be a major decision making tool in knee joint arthritis.

\section{FUNDING STATEMENT}

This study was funded by AbbVie Deutschland GmbH \& Co. KG. AbbVie supported study logistics and approved the final manuscript but did not have any influence on the study design, data analysis or writing of the manuscript.

\section{CONFLICT OF INTEREST}

The authors confirm that this article content has no conflict of interest.

\section{ACKNOWLEDGEMENTS}

We thank Mrs. Imma Fischer, Ph.D., Department of Biostatistics, Tübingen, Germany and the US and clinical research investigators involved in this study. Further we thank all participating physicians and centers for their timeconsuming data acquisition.

\section{REFERENCES}

[1] Backhaus M, Burmester GR, Sandrock D, et al. Prospective two year follow up study comparing novel and conventional imaging procedures in patients with arthritic finger joints. Ann Rheum Dis 2002; 61(10): 895-904. [http://dx.doi.org/10.1136/ard.61.10.895] [PMID: 12228160]

[2] Naredo E, Gamero F, Bonilla G, Uson J, Carmona L, Laffon A. Ultrasonographic assessment of inflammatory activity in rheumatoid arthritis: comparison of extended versus reduced joint evaluation. Clin Exp Rheumatol 2005; 23(6): 881-4. [PMID: 16396709]

[3] Wakefield RJ, Gibbon WW, Conaghan PG, et al. The value of sonography in the detection of bone erosions in patients with rheumatoid arthritis: a comparison with conventional radiography. Arthritis Rheum 2000; 43(12): 2762-70. [http://dx.doi.org/10.1002/1529-0131(200012)43:12<2762::AID-ANR16>3.0.CO;2-\#] [PMID: 11145034]

[4] Hartung W, Kellner H, Strunk J, et al. Development and evaluation of a novel ultrasound score for large joints in rheumatoid arthritis: one year of experience in daily clinical practice. Arthritis Care Res (Hoboken) 2012; 64(5): 675-82. 
[http://dx.doi.org/10.1002/acr.21574] [PMID: 22183834]

[5] Schäfer VS, Fleck M, Kellner H, et al. Evaluation of the novel ultrasound score for large joints in psoriatic arthritis and ankylosing spondylitis: six month experience in daily clinical practice. BMC Musculoskelet Disord 2013; 14: 358. [http://dx.doi.org/10.1186/1471-2474-14-358] [PMID: 24351026]

[6] Szkudlarek M, Klarlund M, Narvestad E, et al. Ultrasonography of the metacarpophalangeal and proximal interphalangeal joints in rheumatoid arthritis: a comparison with magnetic resonance imaging, conventional radiography and clinical examination. Arthritis Res Ther 2006; 8(2): R52.

[http://dx.doi.org/10.1186/ar1904] [PMID: 16519793]

[7] Drossaers-Bakker KW, Kroon HM, Zwinderman AH, Breedveld FC, Hazes JM. Radiographic damage of large joints in long-term rheumatoid arthritis and its relation to function. Rheumatology (Oxford) 2000; 39(9): 998-1003.

[http://dx.doi.org/10.1093/rheumatology/39.9.998] [PMID: 10986305]

[8] Amor B, Santos RS, Nahal R, Listrat V, Dougados M. Predictive factors for the longterm outcome of spondyloarthropathies. J Rheumatol 1994; 21(10): 1883-7.

[PMID: 7837155]

[9] Kapetanovic MC, Lindqvist E, Nilsson JA, Geborek P, Saxne T, Eberhardt K. Development of functional impairment and disability in rheumatoid arthritis patients followed for 20 years: relation to disease activity, joint damage, and comorbidity. Arthritis Care Res (Hoboken) 2015; 67(3): 340-8.

[http://dx.doi.org/10.1002/acr.22458] [PMID: 25186552]

[10] Hauer RW, Schmidt WA, Bohl-Bühler M, et al. Technique and value of arthrosonography in rheumatologic diagnosis. 1: Ultrasound diagnosis of the knee joint. Z Rheumatol 2001; 60(3): 139-47. [http://dx.doi.org/10.1007/s003930170062] [PMID: 11475601]

[11] Backhaus M, Burmester GR, Gerber T, et al. Guidelines for musculoskeletal ultrasound in rheumatology. Ann Rheum Dis 2001; 60(7): 641-9. [http://dx.doi.org/10.1136/ard.60.7.641] [PMID: 11406516]

[12] Backhaus M, Ohrndorf S, Kellner H, et al. Evaluation of a novel 7-joint ultrasound score in daily rheumatologic practice: a pilot project. Arthritis Rheum 2009; 61(9): 1194-201.

[http://dx.doi.org/10.1002/art.24646] [PMID: 19714611]

[13] Aletaha D, Neogi T, Silman AJ, et al. 2010 Rheumatoid arthritis classification criteria: an American College of Rheumatology/European League Against Rheumatism collaborative initiative. Arthritis Rheum 2010; 62(9): 2569-81. [http://dx.doi.org/10.1002/art.27584] [PMID: 20872595]

[14] Hetland ML, Østergaard M, Ejbjerg B, et al. Short- and long-term efficacy of intra-articular injections with betamethasone as part of a treatto-target strategy in early rheumatoid arthritis: impact of joint area, repeated injections, MRI findings, anti-CCP, IgM-RF and CRP. Ann Rheum Dis 2012; 71(6): 851-6.

[http://dx.doi.org/10.1136/annrheumdis-2011-200632] [PMID: 22302316]

[15] Landewé RB, Boers M, Verhoeven AC, et al. COBRA combination therapy in patients with early rheumatoid arthritis: long-term structural benefits of a brief intervention. Arthritis Rheum 2002; 46(2): 347-56. [http://dx.doi.org/10.1002/art.10083] [PMID: 11840436]

[16] Naredo E, Collado P, Cruz A, et al. Longitudinal power Doppler ultrasonographic assessment of joint inflammatory activity in early rheumatoid arthritis: predictive value in disease activity and radiologic progression. Arthritis Rheum 2007; 57(1): 116-24.

[http://dx.doi.org/10.1002/art.22461] [PMID: 17266071]

C Schäfer et al.; Licensee Bentham Open

This is an open access article licensed under the terms of the Creative Commons Attribution-Non-Commercial 4.0 International Public License (CC BY-NC 4.0) (https://creativecommons.org/licenses/by-nc/4.0/legalcode), which permits unrestricted, non-commercial use, distribution and reproduction in any medium, provided the work is properly cited. 